\title{
DISTRIBUIÇÃO DAS PRINCIPAIS CAUSAS DE INTERNAÇÃO HOS- PITALAR DE CRIANÇAS EM FAVELA E NO MUNICÍPIO DE SÃO PAULO, COMO RESULTADO DO PADRÃO DO USO DO SOLO
}

\author{
Maria Aparecida de Oliveira* \\ Mariana Gutierres Arteiro** \\ Helena Ribeiro***
}

\section{RESUMO:}

O artigo apresenta e discute os resultados da análise comparativa em área de favela, no distrito de Vila Andrade e no município de São Paulo, da relação entre a distribuição das dez causas principais de internação hospitalar de crianças, de 1 a 5 anos de idade, e as condições ambientais. Para realização da análise comparativa em três unidades espaciais foram utilizadas informações do censo demográfico 2000, publicado originalmente pelo IBGE (Instituto Brasileiro de Geografia e Estatística), bem como dados extraídos do sistema de internações hospitalares do DATASUS (Base de dados do sistema único de saúde) do ano de 2001, além de fotografias aéreas e levantamento de campo. As análises aplicadas aos dados partiram de alguns pressupostos da geografia médica, utilizando como ferramentas softwares de estatística e de sistemas de informações geográficas. Os resultados obtidos apontaram diferentes causas e magnitudes de internações hospitalares, a partir das taxas do município de São Paulo, do Distrito de Vila Andrade e da favela de Paraisópolis.

\section{PALAVRAS CHAVE:}

Geografia Médica, internações hospitalares, crianças, favelas, SIG, município de São Paulo.

\section{ABSTRACT:}

This paper presents and discusses the results of a comparative analysis in a shanty-town; in an upper class district and in the Municipality of São Paulo, as a whole, of the distribution and of the magnitude of the ten major causes of hospital admissions of children, from one to five years old, and environmental conditions. For the analysis, National Census data from 2000 and data from Information System on hospital admissions of Sistema Único de Saúde (DATASUS) of 2001, air photos and field observation notes were used. References used were those of Medical Geography and techniques used were those of Geographical Information Systems and Statistical software. Results indicated different causes and magnitudes of hospital admissions in the Municipality of São Paulo, in Vila Andrade District and in favela Paraisópolis.

\section{KEYWORDS:}

Medical Geography, hospital admissions, children, shanty-towns, GIS, Municipality of São Paulo.

\section{Introdução}

A segunda metade do século passado, no Brasil, foi marcada entre outros fatores, por um acelerado ritmo de industrialização e o conseqüente ritmo de urbanização. Este período de grande crescimento da população urbana provocou, também, o crescimento das disparidades sociais e ambientais urbanas.

Em menos de meio século, a população nacional deixou de ser rural para tornar-se essencialmente urbana. Este fato gerou, além de outros problemas urbanos, déficits habitacionais, com disseminação de

*Geógrafa pós-graduanda em Geografia Física pelo Departamento de Geografia da FFLCH/USP e pesquisadora do CEPID/FAPESP - Centro de Estudos da Metrópole. E-mail: mariaaparecida@cebrap.org.br

**Tecnóloga em Gestão Ambiental e mestranda pelo Departamento de Saúde Ambiental da USP. E-mail: arteiromg@usp.br ***Geógrafa e professora titular do Departamento de Saúde Ambiental da FSP/USP. E-mail: lena@usp.br 
moradias insalubres, como conseqüência das altas taxas de desemprego das últimas décadas, ocasionadas principalmente pelo alto nível de automação industrial e comercial implementado nas empresas nacionais e multinacionais.

Segundo CALDEIRA (2000 p.211), a segregação, tanto social quanto espacial, é uma característica importante das cidades. As regras que organizam o espaço urbano são basicamente padrões de diferenciação social e de separação. Para esta autora, sobrepostas ao padrão de segregação dos anos 1980 , baseado na relação centro periferia, as transformações recentes estão gerando espaços nos quais diferentes grupos sociais estão muitas vezes próximos, embora separados por muros e tecnologias de segurança, além de apresentarem a tendência a não circular ou interagir em áreas comuns.

A precariedade das condições de trabalho, aliada à ausência ou ineficiência de políticas públicas de incentivo ao pequeno produtor agrícola, entre outros fatores, tem levado milhões de trabalhadores a continuar nas grandes regiões metropolitanas do país, submetidos a diferentes níveis de pobreza urbana. Sua dimensão pode ser analisada tanto pela ótica das disparidades socioeconômicas, como das ambientais, que terão reflexo direto no nível de saúde dos diferentes grupos sociais que habitam a cidade.

Além dos fatores de segregação espacial de ordem socioeconômica, vastamente discutida na literatura sobre pobreza urbana, a exposição de grupos sociais a ambientes degradados e / ou insalubres pode ser considerada uma outra dimensão da pobreza urbana.

O crescimento acelerado das populações urbanas aumentou a pobreza, trazendo enormes conseqüências sociais, nutricionais, ambientais e de saúde, uma vez que um número cada vez maior de pessoas passa a viver em favelas e cortiços superlotados, com acesso limitado a infraestruturas básicas que Ihes permitam uma existência produtiva e saudável (SAWAYA,2002 et. al, p.22).

Para ODUM (1988, p.295), os organismos que compõem um ecossistema não são apenas "escravos" do ambiente físico; eles se adaptam e modificam este ultimo para reduzir os efeitos limitantes de temperatura, da iluminação, da água e de outras condições físicas de existência.

No contexto urbano, os ecossistemas tendem a adquirir novos padrões de funcionamento, como resposta aos usos que são impostos pela ocupação antrópica. Este cenário tem gerado impactos ambientais, criando áreas com ambientes insalubres que têm sido habitadas, preferencialmente, nas grandes cidades, por população de baixa renda. Estas alterações ambientais podem ter efeitos nocivos à saúde humana, sobretudo em crianças, que são mais suscetíveis a efeitos de alteração ambiental.

No interior das grandes cidades, muitas áreas sofrem impactos ambientais, originados das mais variadas ações. Dentre estes impactos, destacamos a contaminação dos corpos d'água e dos solos que, no espaço urbano, pode estar ligada à deficiência ou ausência de saneamento básico.

Apesar dos indicadores nacionais sinalizarem uma melhora nos serviços de saneamento básico, que já tem produzido benefícios ao estado de saúde da população, ainda há, no interior de nossas cidades, um grande contingente populacional que não dispõe de serviços básicos, tais como: ligação regular com rede de abastecimento de água e esgoto e coleta de lixo. Este quadro tem sido observado principalmente em loteamentos irregulares e favelas. 


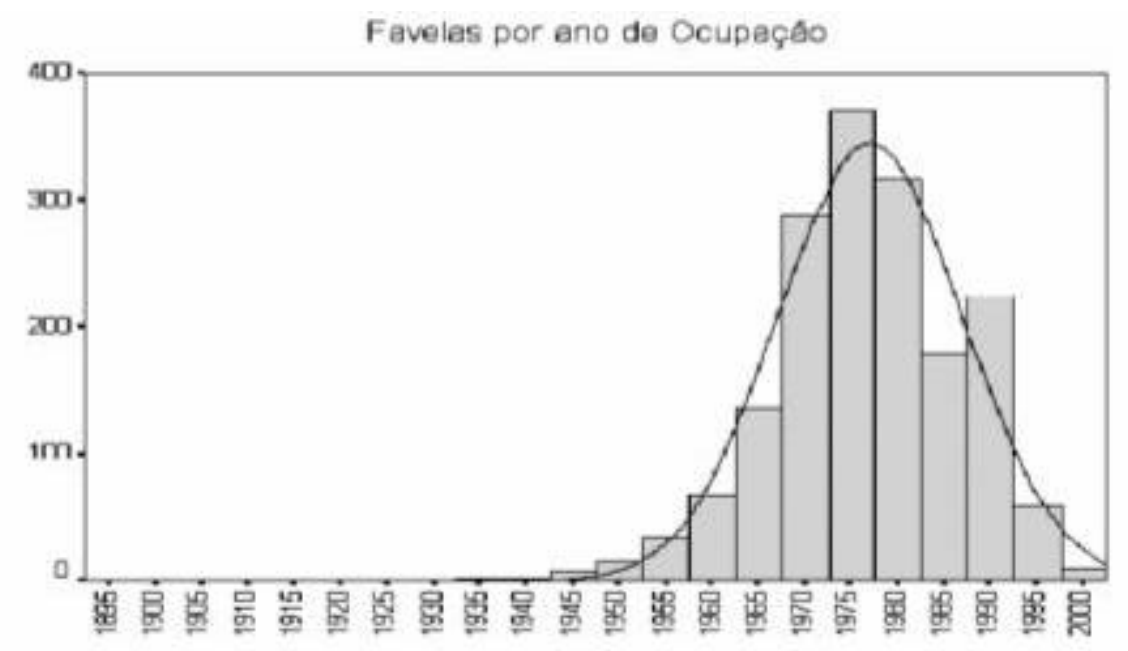

\section{Ano de Ocupaçeo}

Fig. 01 - Favelas por ano de ocupaçẫo Fonte: PMSP, 2003

Organizaçẫo: Maria Aparecida de Oliveira

No interior das grandes e médias cidades brasileiras e, no caso deste estudo, na cidade de São Paulo, as favelas têm sido citadas como áreas portadoras de alto grau de degradação ambiental e baixa cobertura das redes de abastecimento de água, esgoto e coleta de lixo. O crescimento das favelas, como pode ser observado na figura 1 , se deu exatamente num momento de grande expansão da cidade, e seu ápice encontrou-se em meados da década de 1980, que corresponde ao início do período de desemprego crescente no país, que atinge, sobretudo, as grandes capitais.

Para TORRES E MARQUES (2003 p. 65), a população residente em Favelas, no município de São Paulo, corresponde a 1.613.000, aproximadamente $16 \%$ da população municipal. É preciso ressaltar que estes números variam conforme a fonte e métodos utilizados para o cálculo das estimativas, já que o município não dispõe de dados oficiais e atualizados da população real residente em favelas.

Segundo WHO (2002, p. 6), existe uma lista limitada de fatores que têm aumentado o impacto na saúde das crianças como, por exemplo: baixo peso ao nascer; nutrição inadequada; impacto ambiental; pobreza e injustiça.

Saneamento inadequado, moradias precárias, falta de higiene pessoal, problemas freqüentemente agravados pela escassez de água, têm contribuído no desenvolvimento da diarréia, especialmente em crianças. Para WHO (2002, p. 5) os fatores ambientais contribuem significativamente na incidência de mortalidade infantil no mundo.

Segundo RIBEIRO (1996, p. 7), acreditase hoje que o estudo do ambiente, social, natural e construído, é tão importante quanto o estudo dos agentes das doenças. A doença é vista como uma interação entre o agente, o hospedeiro e o ambiente, de forma que os estudos e as ações visando a saúde da população devem, também, enfocar estes três elementos.

A investigação de diferenças entre as doenças relacionadas às internações 
hospitalares pode nos fornecer algumas evidências no tocante à saúde infantil, assim como na indicação de padrões espacialmente diferenciados.

Para RIBEIRO (1996, p.5) a Geografia Médica, na medida em que fornece uma visão mais abrangente do que a sintomatologia, pode ter um papel importante, juntamente com outras ciências, na concepção e no desenvolvimento de políticas de saúde pública, tanto preventivas quanto corretivas.

“A definição da escala de estudo e mapeamento dos diferentes fenômenos é de importância crucial para que se detectem as variações espaciais mais significativas e as relações entre estas e variáveis ecológicas, demográficas, sociais, culturais." (RIBEIRO, 1996, p. 8)

Neste sentido, a realização da análise proposta será desenvolvida a partir de procedimentos baseados em alguns pressupostos da geografia médica com auxílio de técnicas de análise estatística e de geoprocessamento, aplicados aos dados de internações hospitalares do sistema único de saúde (SUS).

A investigação de diferenças entre as doenças relacionadas às internações hospitalares nas três unidades de análise propostas, pode nos fornecer algumas evidências no que se refere à saúde infantil, assim como na indicação de padrões espacialmente diferenciados.

\section{Objetivos}

A partir das Internações hospitalares do ano de 2001, no município de São Paulo, no distrito de Vila Andrade e na Favela de Paraisópolis, buscou-se realizar uma análise comparativa da distribuição espacial das dez causas principais de internação hospitalar, em crianças de 1 a 5 anos de idade, com base nos dados produzidos originalmente pelo DATASUS e georreferenciados pelo Cepid/Fapesp/Centro de Estudos da Metrópole.

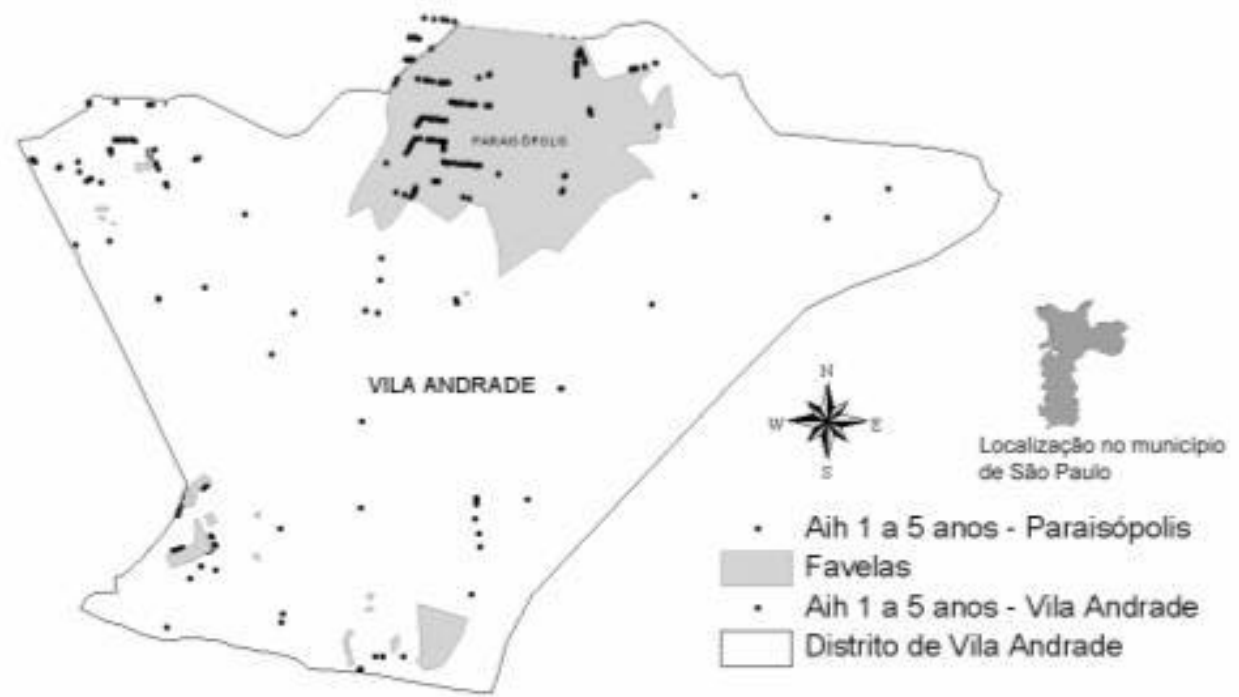

Figura 02 - Localizaçã̃o e caracterizaçã̃o da área de estudos 


\section{Caracterização geral das áreas de estudo}

\section{O município de São Paulo}

O município de São Paulo é a maior capital do país, com uma população, no ano de 2000, de mais de 10 milhões de habitantes. Acreditamos que a cidade já tenha sido suficientemente caracterizada em trabalhos anteriores, de modo que apenas forneceremos alguns dados de saneamento básico e o perfil demográfico da população.

Segundo as informações disponíveis no portal do DATASUS, o município de São Paulo, em 2000, possuía $85 \%$ dos moradores com instalação sanitária ligada à rede geral de esgoto ou pluvial, 3,6\% com fossa séptica, $2,6 \%$ com fossa rudimentar; instalações ligadas a valas, rio, lago e outras totalizavam $8 \%$.

Quanto à coleta de lixo, 99\% das casas têm seu lixo coletado. Em termos dos ecossistemas presentes no município, é possível afirmar, com base no modelo de industrialização e no modo como a urbanização se deu nesta cidade, que estes se encontram completamente alterados, e estas alterações carecem de estudos detalhados para que possamos obter um quadro real da situação ambiental do município, considerando principalmente os impactos destas alterações para a saúde pública.

Em termos socioeconômicos, a cidade é constituída por alto nível de disparidades sociais. Grupos extremamente pobres disputam o espaço urbano com grupos mais abastados e nossa hipótese é que estes diferentes grupos sociais sofrem impactos na saúde, também, de modo diferenciado.

\section{O Distrito de Vila Andrade}

Segundo SILVA, (2003), estudo realizado pela SEHAB/DIAGONAL URBANA (2002), a partir do censo 2000 (IBGE), mostrou que o distrito de Vila Andrade, localizado no
Sudoeste da cidade, apresenta maior desigualdade de renda se comparado ao Morumbi e à Vila Sônia, seus vizinhos. Esse perfil é, provavelmente, influenciado pelas favelas existentes neste distrito; ou seja, 64,7\% dos domicílios de Vila Andrade estão situados em favelas, sendo que Paraisópolis corresponde a $87 \%$ desse total.

Segundo CALDEIRA (2000), nos anos 1980 e 1990, apenas dois distritos da região tiveram crescimento da população: Morumbi $(2,33 \%)$ e Vila Andrade (5,93\%). A autora associa este fato aos grandes investimentos e financiamentos imobiliários destinados à classe média. Edifícios e condomínios de alto padrão foram instalados em Vila Andrade. No entanto, ao mesmo tempo, o distrito observou acentuado aumento da população pobre. Apesar do Morumbi e do distrito de Vila Andrade, segundo CALDEIRA (2000), terem um histórico de ocupação de 25 anos de classe alta, a partir dos anos oitenta, o distrito de Vila Andrade assim como toda a região Sul e Sudoeste, passaram a ser ocupados por um elevado número de favelas.

\section{Condições socioeconômicas e ambientais em Paraisópolis}

Paraisópolis é uma favela que está localizada na região sudoeste do município, no distrito de Vila Andrade. Esta é a segunda maior favela de São Paulo e se encontra num dos distritos de grande concentração de população de alta renda, vizinho ao distrito do Morumbi.

Segundo ALMEIDA (2003), a favela nasceu de um loteamento, em fins dos anos 1930. O loteamento moldou as características geográficas da parte central da favela, formada por quarteirões quadriculados, como qualquer bairro planejado da cidade. As ruas, no entanto, são estreitas para a grande quantidade de pessoas que caminha por elas em seus afazeres cotidianos, disputando o asfalto com os carros, caminhões, ônibus e lotações. A favela possui cerca de 20 ruas principais, no entanto, as áreas 
localizadas mais distantes do seu centro não são asfaltadas. Para acesso aos barracos, no interior das quadras, são utilizadas inúmeras vielas e becos estreitos e, na maioria das vezes, obstruindo córregos.

De acordo com uma pesquisa desenvolvida por ALMEIDA (2003), o perfil etário da favela está bastante concentrado no intervalo entre os 20 e os 44 anos. A faixa de idade mais freqüente é de 25 a 34 anos, sendo este grupo responsável por $40,7 \%$ da PEA (População Economicamente Ativa) da região, ao passo que o grupo mais abrangente - de 20 a 44 anos - comporta $83,2 \%$ da mesma. Este perfil coincide com o perfil geral encontrado na Região Metropolitana de São Paulo, fortemente concentrado entre os 25 e os 40 anos.

A maioria da população é constituída por migrantes nordestinos. No entanto, é interessante destacar o período de residência. $\mathrm{Na}$ pesquisa realizada por ALMEIDA (2003), $12,6 \%$ dos entrevistados tinham até um ano de residência na favela, 6,3\% de 1 a 3 anos; 29,2\% de 3 a 10 anos de residência e 50,2\% residiam na favela há mais de 10 anos.

Segundo o relatório da Prefeitura Municipal de São Paulo, em levantamento realizado no ano de 2003 , na comunidade de
Paraisópolis, predomina o uso residencial. O uso misto e comercial encontra-se geralmente próximo ao eixo viário estruturante. O uso institucional é marcado pela presença de escolas, igrejas e, no caso de Paraisópolis, de algumas instituições de saúde.

Quanto à estrutura dos domicílios, $7,83 \%$ são constituídos de material provisório, 24,23\% de alvenaria precária e o restante considerado de alvenaria boa para consolidação. 0 abastecimento de água, segundo este mesmo relatório, possui na favela um índice de $100 \%$ de abastecimento. A área ocupada pelas favelas conta com rede de distribuição de água e micromedição individual implantada pela SABESP, apenas nos domicílios adjacentes às vias principais, ou seja, os domicílios localizados no interior das quadras são abastecidos de forma clandestina, conforme a figura 05.

Quanto ao esgotamento sanitário, somente as vias oficiais possuem redes coletoras de esgoto, que atendem às construções lindeiras a elas, porém os barracos localizados no interior das quadras são atendidos por canais e tubulações implantados precariamente pelos próprios moradores. As instalações elétricas são precárias, com acentuada presença de gambiarras.

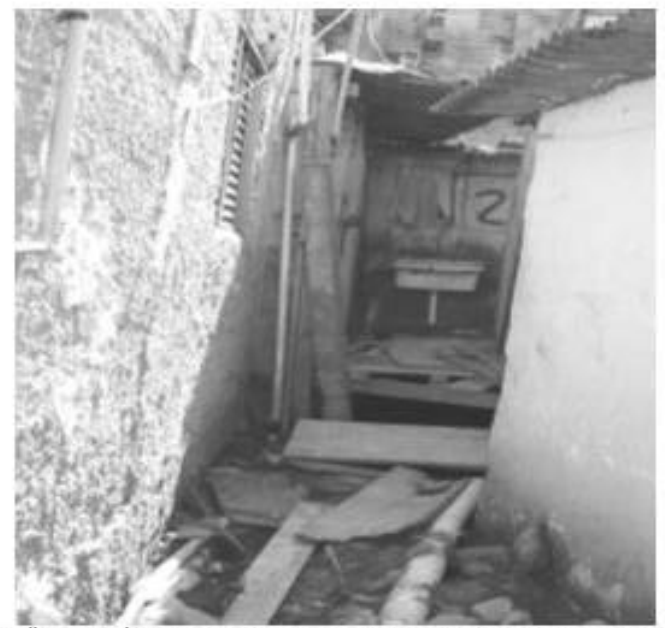

Fig. 03 - Obstruçẫo do córrego do Brejo no interior da favela de Paraisópolis 
Os córregos do Brejo, Antonico e demais córregos de Paraisópolis recebem a descarga oficial e não oficial da rede de esgoto da favela, criando situação de insalubridade. Na figura 03 podemos observar as canalizações precárias realizadas pelos próprios moradores. Nestas, correm água e esgoto e, devido à precariedade, é facilitado o contato da água com o esgoto, gerando um ambiente completamente insalubre.

Segundo SILVA (2004 p.151), uma pesquisa realizada em 1997, pelo IDEM, em Paraisópolis encontrou $16 \%$ das crianças e $19 \%$ dos adultos doentes. O perfil epidemiológico das crianças, de 2 a 5 anos, apresentava pneumonia $(22,6 \%)$, bronquite $(18,6 \%)$, parasitose $(9,3 \%)$, alergia $(8,8 \%)$ diarréia $(4,5 \%)$ deficiência $(3,6 \%)$, anemia $(3,5)$, infestação $(3,5 \%)$, entre outras.

\section{Materiais e métodos}

Para instrumentalização da metodologia, foram utilizadas técnicas de análises espaciais, por meio de Sistema de Informações Geográficas ArcGis 8.2 e de um software de análise estatística SPSS 11.0. Os dados e procedimentos utilizados no desenvolvimento do estudo podem ser observados na figura 04.

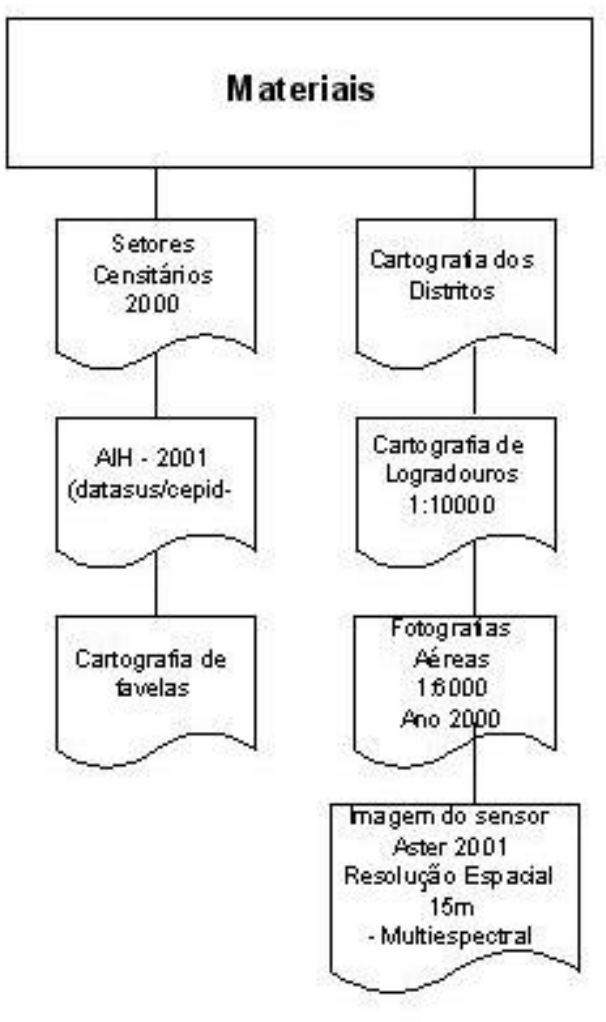

Fig. 04 - Materiais e procedimentos

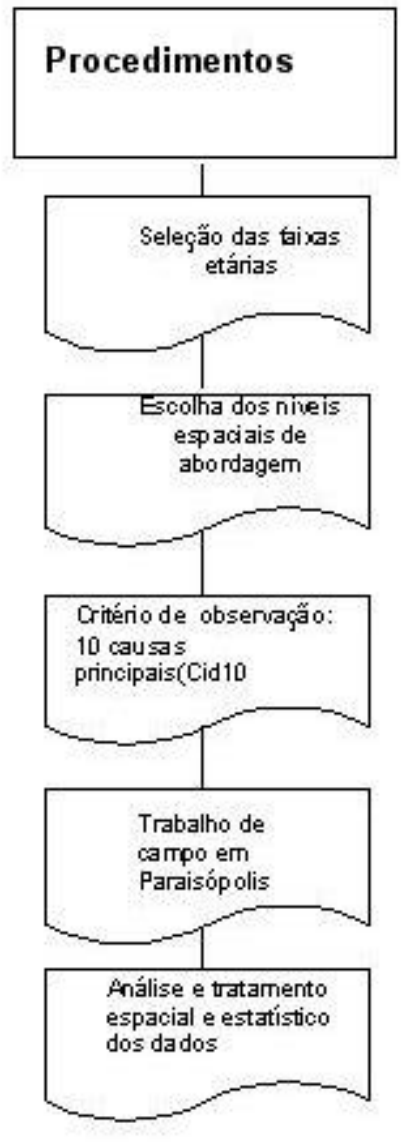


Inicialmente, foram selecionadas da base total de $\mathrm{AlHs}^{1}$ do município de São Paulo, as Internações hospitalares de pacientes com idade entre 1 e 5 anos. Esta operação foi realizada por meio de um sistema de informações geográficas. A partir do resultado da seleção anterior, foram realizadas seleções, considerando o limite espacial das três unidades escolhidas para análise.

As autorizações de Internações Hospitalares $(\mathrm{AlH})$ pertencem a uma base de dados do Sistema de informações hospitalares do Sistema Único de Saúde, produzido pelo Ministério da Saúde, que contém todas as internações hospitalares pagas pelo Sistema Único de Saúde. Neste trabalho utilizamos as internações hospitalares do ano de 2001. É importante destacar que os dados referem-se somente aos hospitais federais e estaduais do município de São Paulo. Os hospitais municipais de São Paulo, até 2001, não integravam o Sistema Único de Saúde.

Para seleção das AlHs referentes ao distrito de Vila Andrade, fiutizado umlayer contendo o limite do distrito censitário, a partir da sobreposição deste ao layer que continha todas as AlHs de São Paulo, desta faixa etária. Como nosso objetivo era comparar as AlHs de Paraisópolis às do distrito de Vila Andrade, na amostra deste distrito excluímos as AlHs contidas no perímetro da favela de Paraisópolis.

A seleção das AlHs localizadas na favela de Paraisópolis foi realizada a partir da utilização do limite da favela, por meio de um arquivo georreferenciado digital da Prefeitura Municipal de São Paulo. Para conferência do limite da favela foi sobreposta à seleção, uma fotografia aérea georreferenciada, contendo a área da favela de Paraisópolis, na escala 1:6.000. Este procedimento visou reduzir os erros de localização devido à precariedade dos endereços contidos na favela.

Deste modo, as AlHs foram divididas segundo as três áreas. Um arquivo continha todos as AIHS do município de São Paulo, outro as AlHs de Vila Andrade (exceto Paraisópolis) e um terceiro arquivo contendo somente as AlHs de Paraisópolis.
Estes arquivos foram inseridos no software SPSS para calculo da freqüência simples, a fim de obter o ranking das dez maiores causas de internação hospitalar por unidade de análise. A causa da internação hospitalar no cadastro do SUS está baseada na Classificação Internacional de Doenças (CID-10).

Este procedimento forneceu o ranking das dez causas principais de internação hospitalar de crianças nas três unidades de análise. No entanto, a utilização da freqüência não nos pareceu conveniente para a realização de correlações entre os tipos de doenças e suas localizações espaciais. Deste modo, optamos por calcular as taxas de internação hospitalar para as três unidades de análise.

A taxa de internação hospitalar foi calculada a partir da obtenção da população total com idade entre 1 e 5 anos de idade, tendo como fonte o censo demográfico IBGE 2000. Os cálculos da população total, da favela de Paraisópolis e de Vila Andrade, foram realizados com o auxílio de um Sistema de Informações Geográficas. A partir destes totais populacionais, calculamos a taxa de internação para cada 1.000 crianças, conforme será apresentado a seguir.

Como a análise dos dados apontava, no caso Paraisópolis, diferenças nos tipos e nas proporções de doenças quando comparado ao município de São Paulo e ao Distrito de Vila Andrade, foi realizado adicionalmente o teste qui-quadrado, com o intuito de verificar significância estatística das diferenças nas proporções das dez causas principais de internação hospitalar, entre a população residente em favelas e a população não residente em favelas para todo o município de São Paulo. O mesmo procedimento foi realizado para o distrito de Vila Andrade. Foi considerado o nível de significância de 0,05.

A variável "reside em favelas" ( $\mathrm{sim} / \mathrm{não}$ ) foi construída e anexada a cada registro das AlH de 2001 do município de São Paulo, de crianças de 1 a 5 anos de idade. Tal variável foi obtida a partir de operações espaciais em Sistemas de Informações Geográficas, utilizando 
os layers de favelas do município de São Paulo do ano de 2001 e o layer com todas AlHs de crianças de 1 a 5 anos de idade do município. É importante destacar que o layer de favelas continha 2018 favelas do cadastro da Prefeitura do Município de São Paulo, em 2001. Com este procedimento, todas as AlHs que estavam localizadas dentro ou a uma distância de 5 metros de alguma favela foram selecionadas. As bases de dados envolvidas em tal procedimento podem ser visualizadas na figura 03.

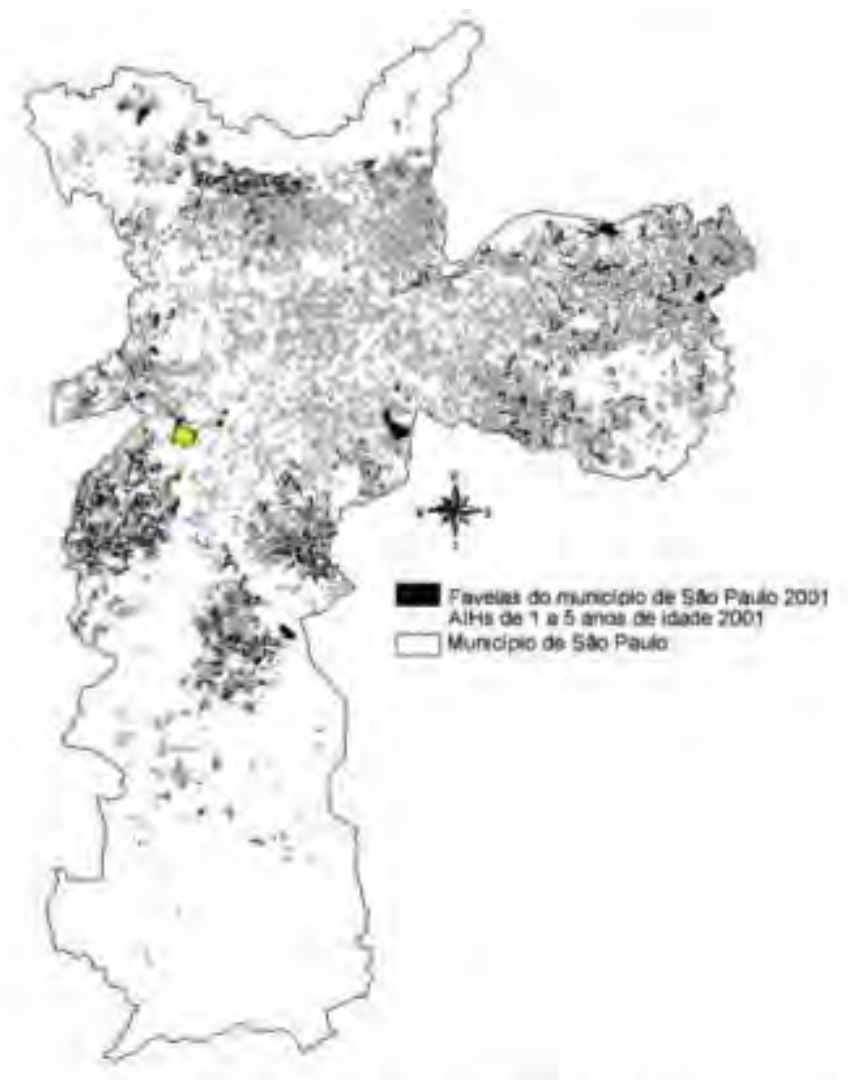

Figura 5 - Bases cartográficas com Favelas no Município de Sẫo Paulo e AlHs de crianças Fontes: PMSP (2001) e DATASUS (2001).

\section{Resultados e discussão}

Os principais resultados obtidos demonstram variações espaciais na distribuição de doenças presentes nas três unidades de análise. No caso do município de São Paulo, a distribuição das causas principais de internação hospitalar tem as doenças do aparelho respiratório ocupando até a terceira posição, totalizando $67 \%$ das causas de internação hospitalar. As internações por diarréia e gastroenterite de origem infecciosa presumível correspondem a $6 \%$ das internações. As doenças relacionadas às condições ambientais totalizam $79 \%$ das internações, as $21 \%$ restantes são doenças não relacionáveis às condições ambientais. 


\begin{tabular}{|c|c|}
\hline Diagnóstico Principal & $\%$ \\
\hline Broncopneumonía & 42,43 \\
\hline Asma & 15,16 \\
\hline Pneumonia & 9,26 \\
\hline Diarréia e gastroenterite orig infecc presumivel & 6,32 \\
\hline Hérnia umbilical siobstrucao ou gangrena & 5,74 \\
\hline Hernia inguinal unilat. siobstr gangrena & 5,33 \\
\hline Bronquite aguda & 5,14 \\
\hline Hipertrofia amídalas cshipertrof adenóides & 3,85 \\
\hline Hêrnia inguinal bilat siobstr ou gangrena & 3,55 \\
\hline Depleçấo de volume & 3,24 \\
\hline
\end{tabular}

Elaboraçäo das autoras

No distrito de Vila Andrade, considerando que foram excluídos os casos de Paraisópolis, o perfil de causas de internação hospitalar apresenta diferenças em relação ao total do município. No entanto, as doenças do aparelho respiratório representam $23 \%$ das internações hospitalares, liderando as causas principais de internação. Já a diarréia e a ascaridíase são responsáveis por $8 \%$ das internações de Vila Andrade.

Tabela 2. - Diaunostico Principal das internaçoes hospitalares de crianças de 1 a 5 anos residentes no. (listrito de Vila Andrade (n=99)

\begin{tabular}{|l|r|}
\hline Diagnóstico Principal & $\%$ \\
\hline Broncopneumonia & 15,15 \\
\hline Asma & 5,05 \\
\hline Diarrëia e gastroenterites origem infecciosas & \\
presumiveis & 4,04 \\
\hline Ascaridiase & 4,04 \\
\hline Pneumonia lobar & 3,03 \\
\hline Hérnia inguinal unilat slobstruçẫo gangrena & 3,03 \\
\hline Colangite & 3,03 \\
\hline Tetralogia de Fallof & 3,03 \\
\hline Meningite viral & 2,02 \\
\hline Inflamação aguda da órbita & 2,02 \\
\hline Fonte: AlH - DATASUS 2001 \\
\hline Elaboração das autoras
\end{tabular}


O aparecimento da ascaridíase como diagnóstico principal de causa de internação chamou a atenção devido ao fato desta doença não aparecer no interior da Favela de Paraisópolis, e nem no município de São Paulo.
O distrito de Vila Andrade, além de Paraisópolis, possui outras favelas que depositam os dejetos diretamente em córregos. A ascaridíase é uma doença relacionada à falta de saneamento e higiene, conforme aponta o quadro 01.

Quadro 1. - Doenças causadas por falta de esgoto e os modos de transmissão

\begin{tabular}{|c|c|}
\hline Doengas & Modos de trangmissáo \\
\hline Anebiase & Thgestäo de agua ou de alimentos contaminados, moscas, mäos sujas \\
\hline Ancilolostomiase & Contato com o solo contaminado \\
\hline iscaidiase & Ingestâo de avos contidos no solo e nos alimentos \\
\hline Cóléra & Ingestäo de agua ou de alimentos contarninados, mäos sujas, moscas \\
\hline $\begin{array}{l}\text { Diarreias } \\
\text { inteociosas }\end{array}$ & Ingestäo de agua ou de alimentos contarninados, mäos sujas, moscas \\
\hline Escuistossomose & Contato da pele ou mucosas com àgua comaminada \\
\hline Febre tifoide & Ingestâo de agua ou de alimentos contarninados, mâos sujas \\
\hline Febre paratióide & Ingestao de agua ou de alimentos contarninados, manos sulas \\
\hline Giardiase & $\begin{array}{l}\text { Atraves das mäos contarninadas por fezes contendo sistos, agua e alimentos na transmissao } \\
\text { indireta }\end{array}$ \\
\hline Hepattre intecciosa & Contaminacăo fecal-ali ingestäo de àg la e alimentos contaminados \\
\hline Boliomelite & (nadretamente, atraves da ingestäo de ägua contaminada (considerada erradicada no Erasil) \\
\hline Teniase & $\begin{array}{l}\text { Came de animás doentes (que se alimertarn de fezes), transteréncia direta da mäo à boca; } \\
\text { ingestâo de água ou de alimentos contaninados }\end{array}$ \\
\hline
\end{tabular}

Fonte: Mota, 1999,

Como os córregos constituem ecossistemas que estão ligados a outros ecossistemas, ou seja, a outros córregos pertencentes a uma mesma bacia hidrográfica, o lançamento de esgoto e outras substâncias nos corpos d'água pode estar contribuindo para o aparecimento desta doença no distrito. I sto sugere que os impactos oriundos do lançamento de esgoto in natura diretamente nos corpos d' água pode causar conseqüências em áreas externas à área diretamente afetada.

Contraditoriamente, outro elemento que merece destaque em Vila Andrade é o aumento no número de doenças não relacionadas às condições ambientais, quando comparadas às doenças que aparecem no contexto do município de São Paulo e da favela de Paraisópolis.
As dez causas principais de internação hospitalar, na favela de Paraisópolis, apresentam magnitudes diferenciadas, quando comparadas ao município de São Paulo e ao Distrito de Vila Andrade. A broncopneumonia ocupa a primeira posição, como nos dois casos anteriores. No entanto, diarréia e gastroenterite de origem infecciosa presumível ocupam o segundo lugar no ranking das dez causas principais de internação hospitalar. Outro fator que merece destaque é o fato de que todas as doenças possuem relação com condições ambientais, com exceção do diagnóstico classificado por Outras convulsões não especificadas. 


\begin{tabular}{|c|c|}
\hline Diagnóstico Principal & $\%$ \\
\hline Broncopneumonia & 30,15 \\
\hline $\begin{array}{l}\text { Diarréia e gastroenterite orig infecciosa presumida } \\
\text { Bronquite aguda }\end{array}$ & $\begin{array}{l}14,71 \\
13,24\end{array}$ \\
\hline Pneumonia & 11,03 \\
\hline Qutras doenças dos brônquios NCOP & 8,09 \\
\hline Pneumonia lobar & 5,88 \\
\hline Outras convulsôes NE & 5,88 \\
\hline Asma NE & 3,68 \\
\hline Outros transtournos respiratónios específicos & 3,68 \\
\hline $\begin{array}{l}\text { Desconforto espiratónio NE do recém-nascido } \\
\text { Fonte: DATASUSICEPIDIFAPESPICentro de Estudos de } \\
\text { Elaboração das autoras }\end{array}$ & $\frac{3,68}{\text { opole }}$ \\
\hline
\end{tabular}

\section{Análise comparativa das taxas de internação hospitalar baseada no diagnóstico principal}

Devido às limitações da análise com base somente nos percentuais de internações, que não nos permite observar a magnitude dos eventos, optamos por calcular a taxa de internação hospitalar das dez causas principais, utilizando para tanto as informações demográficas presentes na base de setores censitários do IBGE (2000). A taxa de internação hospitalar para o município de São Paulo e os distritos foi expressa em n/1.000 habitantes.

Em São Paulo, a taxa de internação hospitalar por broncopneumonia é de 6/1.000 hab. No distrito de Vila Andrade esta taxa cai para 4,5/1.000 habitantes e na Favela de Paraisópolis, esta taxa sobe para 9/1.000 habitantes.

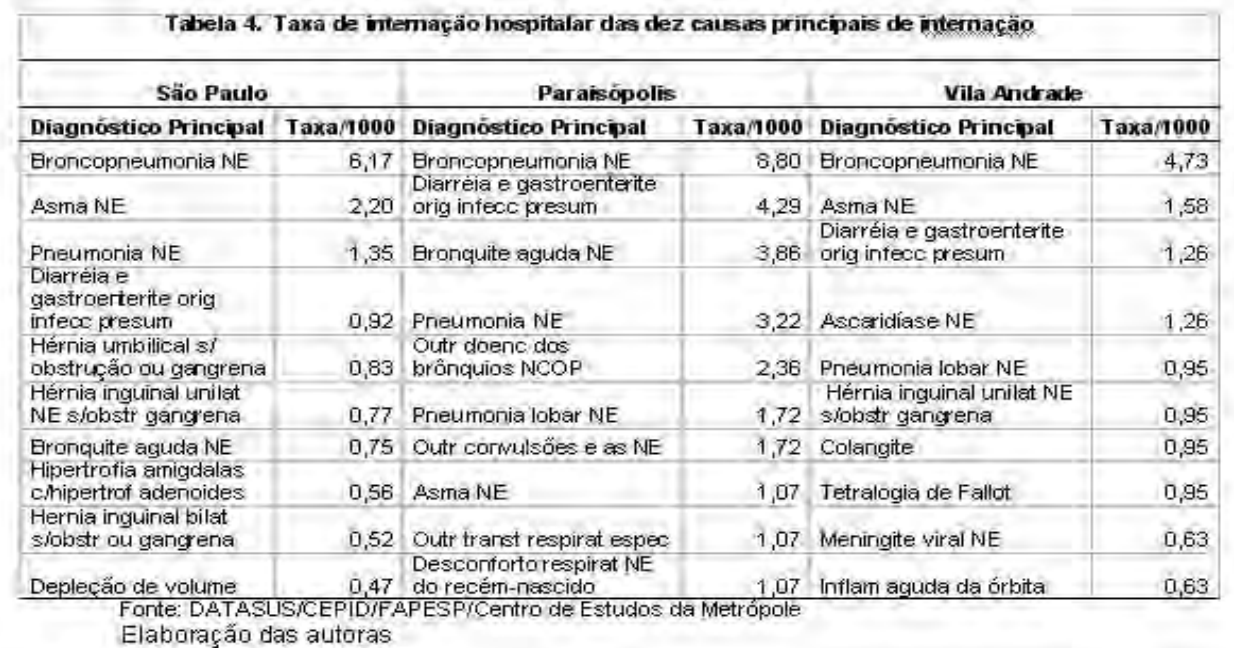


No distrito de Vila Andrade, as maiores taxas de internação ocorrem devido a doenças do aparelho respiratório, seguindo o ritmo da cidade. No entanto, comparando com o município de São Paulo, observa-se que, em Vila Andrade, as taxas de internação hospitalar por doenças do aparelho respiratório são bem mais baixas do que as da cidade de São Paulo. Novos estudos são necessários para avaliarmos melhor este aspecto. No entanto, podemos dizer que esta diferença em relação às taxas pode estar relacionada às condições climáticas do distrito. O distrito de Vila Andrade possui uma das maiores taxas de concentração de área verde do município. Talvez a vegetação, neste distrito, exerça funções de filtro, reduzindo assim os níveis de poluentes no ar e contribuindo para a composição de um clima mais ameno do que no restante da cidade.

Além das taxas de internação serem menores, outro fator importante é o maior número de doenças não relacionadas diretamente com o meio ambiente.

As taxas de internações hospitalares obtidas para Paraisópolis revelaram o inverso da situação anterior. Entre as dez causas principais de internação hospitalar, oito são relacionadas a problemas do aparelho respiratório, apresentando para todas as doenças, com exceção da asma, as maiores taxas de internação hospitalar em relação ao município de São Paulo e ao Distrito de Vila Andrade.

A taxa de internação hospitalar por diarréia e gastroenterites é a segunda maior em Paraisópolis. Estas doenças são de possível veiculação hídrica, e podem ser resultantes da ausência de coleta e afastamento do esgoto sanitário e de fornecimento de água adequadamente, ou mesmo da ineficiência na coleta de lixo, expondo as crianças a situações de insalubridade. No entanto, pesquisas qualitativas devem ser desenvolvidas com o intuito de melhor avaliar estas considerações.
Num estudo com crianças moradoras em favelas no Jardim Leonor, em São Paulo, NETO (1996) encontrou elevadas incidências de parasitas intestinais e bactérias enteropatogênicas nas fezes de crianças que vivem em comunidades desprovidas de condições sanitárias apropriadas.

As doenças do aparelho respiratório, em Paraisópolis, podem estar relacionadas ao microclima local da favela que, segundo SILVA (2004, p. 152), não é favorável ao conforto térmico da população residente, pela falta de ventilação e de iluminação natural, pelas condições atmosféricas representadas por temperaturas mais altas e mais baixas que no entorno, pela umidade elevada em alguns pontos e pela falta de arborização.

Condições habitacionais inadequadas podem acentuar efeitos de ilhas de calor e de frio, sobretudo sob climas tropicais. Inadequação de isolamento térmico e de ventilação tornam mais severos os elementos do micro-clima e, conseqüentemente, seus efeitos sobre a saúde humana, (RIBEIRO,1996, p.15).

É interessante destacar que o grande número de doenças infecciosas, que os dados demonstram, nesta faixa etária, pode inclusive contribuir para o aparecimento ou prevalência de desnutrição, com repercussão no crescimento e desenvolvimento das crianças.

Os resultados obtidos no estudo apontaram para diferenças significativas entre as dez causas principais de internação hospitalar no caso de Paraisópolis. Como dispúnhamos dos dados para todos os municípios de São Paulo, tanto de internações hospitalares como um mapa com todas as favelas do município em 2001, julgamos ser pertinente a aplicação do teste qui-quadrado, conforme descrito em materiais e métodos.

O teste qui-quadrado aplicado mostrou diferenças na distribuição das causas e magnitudes das internações hospitalares entre crianças de um a cinco anos de idade residentes 
e não residentes em favelas, no município de São Paulo $(p=0,004)$. Da mesma forma, ao se aplicar o teste com os dados apenas do distrito de Vila Andrade, foram encontradas diferenças nas proporções das principais causas de internação hospitalar entre crianças residentes em favelas e entre as não residentes em favelas $(p=0,047)$. Desta forma, pode-se concluir que as principais causas de internação hospitalar de crianças de um a cinco anos moradoras de favelas do município de São Paulo são diferentes do que das crianças não moradoras de favelas.

\section{Considerações finais}

Em que pese a amostra estudada cobrir somente a população atendida pelo SUS, com dados dos hospitais estaduais e federais, consideramos que os resultados obtidos oferecem indícios da relação entre saúde e meio ambiente na favela de Paraisópolis, apontando para uma piora das condições de saúde das crianças residentes neste espaço. Estes resultados, somados aos obtidos com o teste qui-quadrado, apontam a importância das condições ambientais, vinculados ao padrão de uso da terra.

O estudo demonstrou, também, que os dados ainda não são suficientes para uma análise dos pontos mais críticos da favela, que propiciariam um maior risco à saúde da população local, pois as AlHs referem-se a códigos de endereçamento postal e não a números de casas nas ruas e vielas. No entanto, indicam a pertinência da utilização de abordagens que considerem recortes espaciais e escalas diferenciadas na detecção de diferentes padrões e ocorrências de doenças.

Há necessidade de realização de pesquisas minuciosas sobre o saneamento, as condições de habitação, os hábitos de higiene e os costumes da população, o acesso ao atendimento médico, entre outros fatores que podem influenciar na saúde pública.
Em todas as unidades espaciais, as doenças relacionadas ao aparelho respiratório ocuparam as prin eiras posiģões noranking das dez causas de internação, nesta faixa etária, que parece ser uma tendência em todas as cidades industriais. No entanto, podemos afirmar, com base nestes resultados, que a população infantil de Paraisópolis tem sofrido, numa escala maior, os efeitos das condições ambientais insalubres em que vivem.

Apesar das melhorias nos indicadores de saúde ocorridas nas últimas décadas, principalmente devido à expansão das redes de água e esgoto, ao observar a cidade como um todo, muitas diferenças no tocante à distribuição de doenças, assim como às suas magnitudes, mascaram as realidades intra-urbanas.

Estudos que considerem variações espaciais das doenças podem contribuir para a formulação de políticas públicas, que realmente atinjam a população de baixa renda que vive nestes ambientes e conseqüentemente melhorem a sua qualidade de vida. Os exemplos de Vila Andrade, que apesar de ser um dos distritos mais ricos do município, ainda possui, no ranking das dez causas principais de internação, doenças como a ascaridíase e da cidade de São Paulo, com presença de doenças diarréicas e gastrenterite de origem infecciosa presumível, demonstram que é necessário agregar aos cuidados à saúde, além dos métodos tradicionais, a melhoria das condições ambientais.

Estes resultados indicam a relevância de métodos geográficos para diagnósticos de saúde pública com a incorporação de variáveis ambientais.

Um caminho interessante seria a realização de estudos longitudinais, que considerassem uma amostra de crianças, com a realização de exames clínicos, aplicação de questionários, visitas domiciliares, diagnósticos ambientais detalhados, a fim de melhor relacionar as condições de saúde às condições ambientais. 


\section{Notas}

1 Autorização de internação hospitalar.

\section{Bibliografia}

ALMEIDA, R. et. Alli. "Características de Paraisópolis e de seus moradores". In Comin, Alvaro A. (coord.) Desenvolvendo mecanismos de inclusão social na nova ordem metropolitana. Cebrap, Convênio Cebrap/Finep, I Relatório (mimeo). 2003.

BRASIL- Perfil da Saúde Ambiental Infantil no Brasil. Relatório do Ministério da Saúde do Brasil. Brasilia, 2003

CALDEIRA, T. P. Cidade de muros: crime, segregação e cidadania em São Paulo. Tradução Frank de Oliveira e Henrique Monteiro. São Paulo. Ed. 34/Edusp. 2000.

DATASUS - Banco de Dados de Autorização de Internação Hospitalar, disponível em <http:// datasus.gov.br> último acesso em 12/04/2004.

DATASUS/CEPID/FAPESP/Centro de Estudos da Metrópole. Cadastro georreferenciado de Internações hospitalares do município de São Paulo 2001. Cd -rom. São Paulo. 2004.

FERREIRA, M.U., FERREIRA, C. S. e MONTEIRO, C. A. Tendência secular das parasitoses intestinais na infância na cidade de São Paulo (1984-1996). Rev. Saúde Pública. [online]. dez. 2000, vol.34, no.6, supl. [citado 11 Abril 2004], p.73-82. Disponível na World Wide Web: <http:/ / $w$ w w . s c i e l o s p . o r scielo.php? script $=$ sci_arttext $\&$ pid $=S 0034$ $89102000000700010 \& \ln \mathrm{g}=\mathrm{pt} \& \mathrm{nrm}=$ iso $>$. ISSN 0034-8910. 2000.

IBGE - INSTITUTO BRASILEIRO DE GEOGRAFIA E ESTATÍSTICA. Censo Demográfico 2000. Rio de Janeiro, 2000.
MOTA, S. "Saneamento". In: ROUQUAYROL, M. Z., Epidemiologia e saúde, 5a edição Rio de Janeiro: Medsi, pp 405-430, 1999

NETO, U. F. - “Enteropatia ambiental". Uma conseqüência do fracasso das políticas sociais e de Saúde Pública. Rio de Janeiro. Ed. Revinter. 1996.

RIBEIRO, H. I lha de calor na cidade de São Paulo: sua dinâmica e efeitos na saúde da população. Tese de Livre Docência. Faculdade de Saúde Pública da Universidade de São Paulo. 1996.

SAWAYA, A. L. ; SOLYMOS, G. M. B. ; MARTINS, P. A. ; FLORÊNCIO, T. M. T. . Os Dois Brasis: Quem São, Onde Estão e Como Vivem os pobres Brasileiros. Revista Estudos Avançados. Estudos Avançados, São Paulo, v. 17, n. 48, p. 21-44, 2003.

SILVA, E. N. . Aspectos do Microclima em ambientes externos de favela, visando subsidiar avaliação dos efeitos na saúde dos moradores: o caso de Paraisópolis, São Paulo, Brasil. Dissertação de Mestrado. Faculdade de Saúde Pública, Universidade de São Paulo. 2004.

TORRES, H. MARQUES, E “Tamanho populacional das favelas paulistanas. Ou os grandes números e a falência do debate sobre a metrópole". Ouro Preto: trabalho apresentado no Encontro da Associação Brasileira de Estudos Populacionais - Abep. 2002.

WHO. Child Health Research - A Foundation for Improving Child Health. Geneva, 2002

Trabalho enviado em agosto de 2007

Trabalho aceito em setembro de 2007 